\title{
Bayesian estimates of genetic variance of fertility and hatchability under a threshold animal model ${ }^{*}$
}

\author{
A. Dobek ${ }^{1}$, M. Szydłowski ${ }^{2}$, T. Szwaczkowski ${ }^{2}$, E. Skotarczak ${ }^{1}$ \\ and K. Moliński ${ }^{1}$
}

\author{
August Cieszkowski Agricultural University of Poznań \\ ${ }^{1}$ Department of Mathematical and Statistical Methods \\ Wojska Polskiego 28, 60-637 Poznań, Poland \\ ${ }^{2}$ Department of Genetics and Animal Breeding \\ Wotyńska 33, 60-637 Poznań, Poland
}

(Received 8 November 2002; revised version 5 March 2003; accepted 4 April 2003)

\begin{abstract}
The genetic variability of fertility and hatchability of laying hens were studied in four strains under long-term selection for productive traits. Data were collected over nine generations. The total number of individuals recorded per strain ranged from 2015 to 5386. The traits were analysed as binary characters under the threshold animal model using Gibbs sampling. The point estimates of heritability of fertility were relatively high and ranged from 0.38 to 0.46 . The estimates for hatchability were lower and ranged from 0.22 to 0.24 . All the strains showed positive genetic trends.
\end{abstract}

KEY WORDS: genetic trend, genetic variance, Gibbs sampling, laying hens, threshold model, heritability

\section{INTRODUCTION}

Contrary to mammal species, laying hens have immense natural fecundity, short generation interval, mechanized incubation and brooding, persistent fertility etc. (Hartmann, 1989). Hence, over the last decades a breeders' interest has focused on genetic improvement of egg production traits. This, however, might be associated with an unfavourable correlated genetic response of others traits (Chaudhary et al., 1987). Sewalem et al. (1998) showed that in some lines fertility and hatchability were impaired by selection for egg production.

* Supported by the State Committee for Scientific Research, Grant No. 5P06D02019 
The genetic background of layer reproductive traits has been investigated in several studies (Beaumont et al., 1997; Szwaczkowski et al., 2000). The fertility and hatchability are considered as traits determined by a number of loci and environmental effects. Both traits show low or moderate heritability and no or weak genetic correlation with production traits (Yoo and Wienties, 1991; Foerster, 1993). Most estimates found in literature are based on the methods developed for continuous traits.

Both fertility and hatchability have a simple binary phenotypic expression but are often recorded for layers as percentage traits, e.g. percentage of fertilized/hatched eggs per individual. Thus, classical linear methodology for continuous traits has often been employed, ignoring the binary nature of these reproductive traits. Theoretically, linear models are inadequate for binary data, but with exact methods they are less computationally demanding than the more appropriate threshold models (Gianola and Foulley, 1983).

Over last years, the Bayesian approach and Markov Chain Monte Carlo algorithms have been recommended for analysis of animal data. These methods have several advantages, e.g. a more complex genetic model can be applied with less difficulty, larger data sets can be analysed, no solution to the mixed model equations is needed (e.g. Van Tassel et al., 1995).

In this paper we estimated the heritability of fertility and hatchability of laying hens under the threshold animal model by the use of Gibbs sampling. The annual averages of breeding values were estimated as well.

\section{MATERIAL AND METHODS}

The data sets were collected on Pedigree Laying Hen Farm of Rujsca (West Poland) in 1989-97. The following four layer strains were included in the study: H77 (Leghorn), N88 (New Hampshire), R33 (Rhode Island Red) and S22 (Sussex). All strains had been under long term selection for performance traits (initial egg production, rate of initial egg production, average egg weight, age at first egg, body weight). The percentage of fertilized eggs and percentage hatched of set eggs were recorded. The percentage of fertilized eggs was examined by candling on day 8 of incubation. The exact number of egg per layer over the period was not available. Therefore, to obtain a binomial phenotypic scale 30 eggs (average hatch egg per individual) per layer were considered. The number of observations per generation (year) was relatively small as both traits were registered only for dams chosen as parents (16303 dams within four strains were recorded). The data recorded in 1991 (strain R33) and 1992 (strain S22) were not available. A one-year generation interval was applied. Environmental conditions had not varied considerably. Descriptive statistics of the data sets are shown in Table 1. 
Number of individuals recorded (n), averages and standard deviations (SD)

\begin{tabular}{|c|c|c|c|c|c|c|}
\hline \multirow{3}{*}{ Strain } & \multicolumn{6}{|c|}{ Trait } \\
\hline & \multicolumn{3}{|c|}{ fertility, $\%$} & \multicolumn{3}{|c|}{ hatchability, \% } \\
\hline & $\mathrm{n}$ & average & SD & $\mathrm{n}$ & average & SD \\
\hline H77 & 4522 & 87.6 & 17.1 & 5386 & 75.3 & 16.5 \\
\hline N88 & 3463 & 89.4 & 17.5 & 3441 & 78.6 & 15.3 \\
\hline R33 & 2040 & 87.3 & 17.7 & 2015 & 69.4 & 19.7 \\
\hline S22 & 4414 & 82.9 & 20.0 & 4333 & 66.9 & 20.3 \\
\hline
\end{tabular}

\section{Model}

The fertility and hatchability were treated as binomial traits and described with the threshold animal model. Following the theory of the threshold models we assumed an unobservable continuous variable - liability, being the sum of unknown genetic and environmental effects. The variable has a fixed threshold, which partitions the scale into two intervals corresponding to the two possible phenotypes (Sorensen et al., 1995; Matos et al., 1997). Without loss of generality, the threshold was taken equal to zero. Following the unitrait animal model, the liability was modelled as

$$
w_{i j}=\mathbf{x}_{l}^{\prime} \boldsymbol{\beta}+\mathbf{z}_{i}^{\prime} \mathbf{a}+\mathrm{e}_{i j} \quad i=1,2, \ldots, m ; \quad j=1,2, \ldots, \mathrm{n}_{\mathrm{i}}
$$

where: $w_{i j}$ is connected with $\mathrm{y}_{i j}$ which takes value 1 or 0 (e.g. fertilized or unfertilized), $\boldsymbol{\beta}$ is a $p$-vector of fixed effects including the years and hatch periods, $\mathbf{a}$ is a $q$-vector of random additive genetic effects, $\mathbf{x}_{l}$ and $\mathbf{z}_{i}$ are vectors choosing the appropriate fixed and random effects and $\mathrm{e}_{i j}$ is a random error with 0 expectation and variance equal to 1 . The random additive genetic effects follow a normal distribution $N\left(\mathbf{0}, \mathbf{A} \sigma_{a}^{2}\right)$, where $\mathbf{A}$ is the additive relationship matrix. The parameters of the model were estimated by Gibbs sampling, using the algorithm described by Moliński et al. (2003). The algorithm provides samples of the unknown parameters from their approximated marginal distributions. The point and 95\% interval estimates of heritability were based on the samples collected.

\section{Computational details}

Two independent chains of 100,000 rounds each were generated. The chains differed with respect to the initial additive genetic variance (2.0 and 0.01$)$ and the seed for the random number generator. The starting additive genetic values were set to zero. The first 10,000 rounds were discarded as the burn-in period. The 
burn-in period was based on the visual evaluation of values of additive genetic variance plotted against iteration. Samples were taken at 10-round intervals. These were highly autocorrelated samples but provide unbiased estimate of the posterior distribution and its summaries. Point estimates of the parameters were calculated as the means of samples or functions of samples. For each individual two estimates of the additive genetic effects were obtained using samples from the two chains. The differences between estimates were monitored to check the convergence of Gibbs sampling (Moliński et al., 2003). Final estimates for heritabilities $\mathrm{h}^{2}=\sigma_{a}^{2} /\left(\sigma_{a}^{2}+1\right)$ and additive genetic effects were based on combined samples from the two chains. The samples were used to estimate the posterior distributions and the credible sets - Bayesian credible intervals. Monte Carlo error measures the variability of point estimates due to the length of the Gibbs chain. Monte Carlo error was calculated as the standard deviation of the mean of samples that were thinned to a lag correlation of 0.01 . The thinning rate was based on the nonlinear estimation of the lag correlation (Van Tassell et al., 1998). The genetic trend was obtained by averaging the predictors of individuals' additive genetic effects within each generation (year).

\section{RESULTS AND DISCUSSION}

The estimates of heritabilities (and their 95\% Bayesian credible sets) are shown in Table 2. The estimated heritabilities for fertility are high. The direct additive heritability estimates of fertility obtained under the threshold model reported in literature ranged from 0.14 (Hartmann, 2002) to 0.35 (Sewalem, 1998). In general, the heritabilities estimated for continuous data (expressed as percentage of fertilized eggs) are lower. In the study of Piotrowski and Szwaczkowski (2002) the REML heritability estimates ranged from 0.08 to 0.12 and the so-called total heritability, which includes the variability due to the correlated maternal additive genetic effects, were only slightly higher (from 0.11 to 0.13 ).

The comparison of heritabilities of fertility across studies is difficult due to a difference in the way the measurements were taken and different methods used for estimation. The classification applied in this study (based on candling on day 8 of incubation) treated early-mortared embryos as unfertilized eggs. Jassim et al. (1996) reported that about $65 \%$ of embryonic mortality occurs in two phases with peaks at 4-th and 19-th day of incubation. Brah et al. (1999) found heritability estimates (0.00-0.17) for early mortality across lines, generation and methods of estimation to be quite variable. Most reports on heritability estimates of the fertility traits were performed by the use of a simple genetic model (sire and sire-dam). It must be remembered, however, it may lead to biased estimates. 
TABLE 2

The heritability estimates - marginal posterior means, lower and upper cutoffs for $95 \%$ credible sets and Monte Carlo error (MCE)

\begin{tabular}{lcccc}
\hline Trait/strain & Mean & $\begin{array}{l}\text { Lower } \\
\text { cutoff }\end{array}$ & $\begin{array}{l}\text { Upper } \\
\text { cutoff }\end{array}$ & MCE \\
\hline Fertility & & & & \\
H77 & 0.4369 & 0.4237 & 0.4501 & 0.0021 \\
N88 & 0.4640 & 0.4462 & 0.4814 & 0.0033 \\
R33 & 0.4209 & 0.4002 & 0.4420 & 0.0028 \\
S22 & 0.3819 & 0.3688 & 0.3951 & 0.0042 \\
& & & & \\
Hatchability & & & & \\
H77 & 0.2389 & 0.2284 & 0.2495 & 0.0031 \\
N88 & 0.2224 & 0.2095 & 0.2351 & 0.0042 \\
R33 & 0.2297 & 0.2143 & 0.2450 & 0.0032 \\
S22 & 0.2445 & 0.2336 & 0.2549 & 0.0045 \\
\hline
\end{tabular}

In case of hatchability the differences in heritabilities among strains were small. In all strains the estimates were lower than for fertility. This is in agreement with most results reported in the literature (Sewalem, 1998). In a few cases only the different tendency was observed (Szwaczkowski et al., 2000). Hatchability is a trait more affected by environmental condition and egg composition than fertility (Hartmann et al., 2002). Therefore, it can be concluded that heritability decreased because environmental variation during incubation increased faster than genetic variation. The study of related traits confirms this conclusion. Beaumont et al. (1997) and Brah et al. (1999) reported that heritability of early embryonic mortality was higher than heritabilities at later stages.

It is well known that the reproductive traits give usually low heritability estimates. It can be partly explained by the fact, that the linear model is inappropriate for binomial data. Normality of residuals is the main assumption in linear models. Szwaczkowski and Piotrowski (1998) found that both untransformed and arcsinsquared transformed reproductive traits do not hold this assumption. Non-normality leads to higher residual variance estimates and in consequence to the underestimation of heritability (Van Heelsum et al., 2001). From this perspective, the number of heritability estimates reported in literature may be underestimated. It is also known from the literature that the genetic parameters for various performance traits obtained with the threshold model are higher than the estimates from linear model (Matos et al., 1997). So, the threshold approach seems to be more appropriate. Furthermore, Bayesian variance estimates tend to be higher compared to the often used restricted maximum likelihood estimates (Wright et al., 2000).

Generally, the analysed layers showed positive genetic trends when first and last annual average breeding values are compared (see Figures 1 and 2). How- 


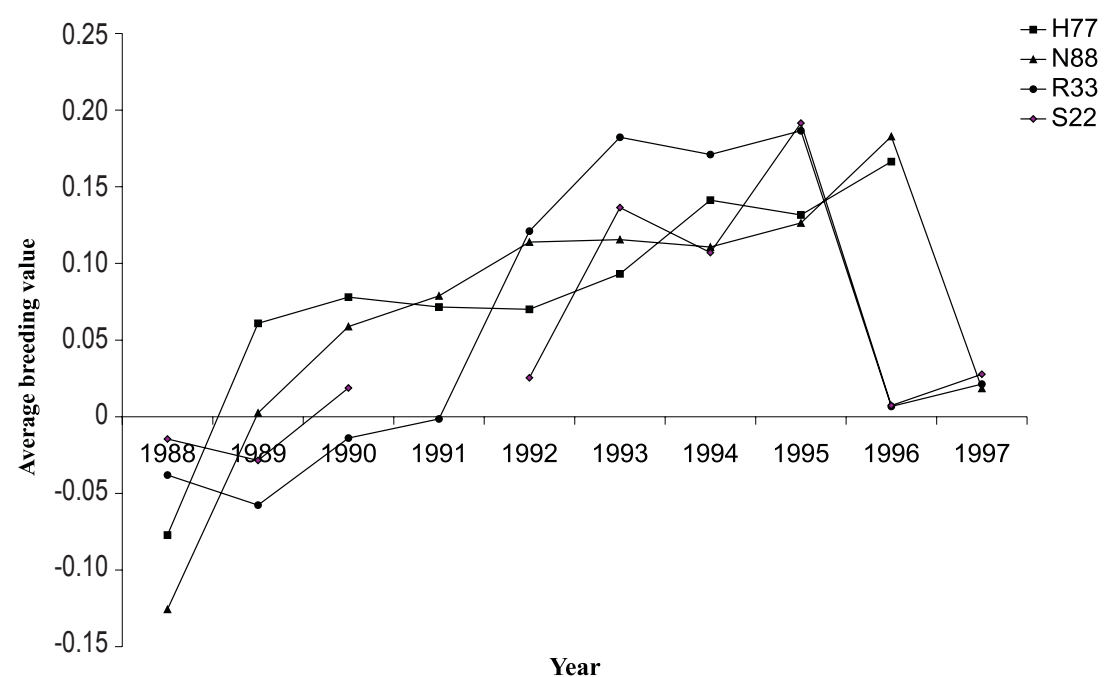

Figure 1. Genetic trends for fertility

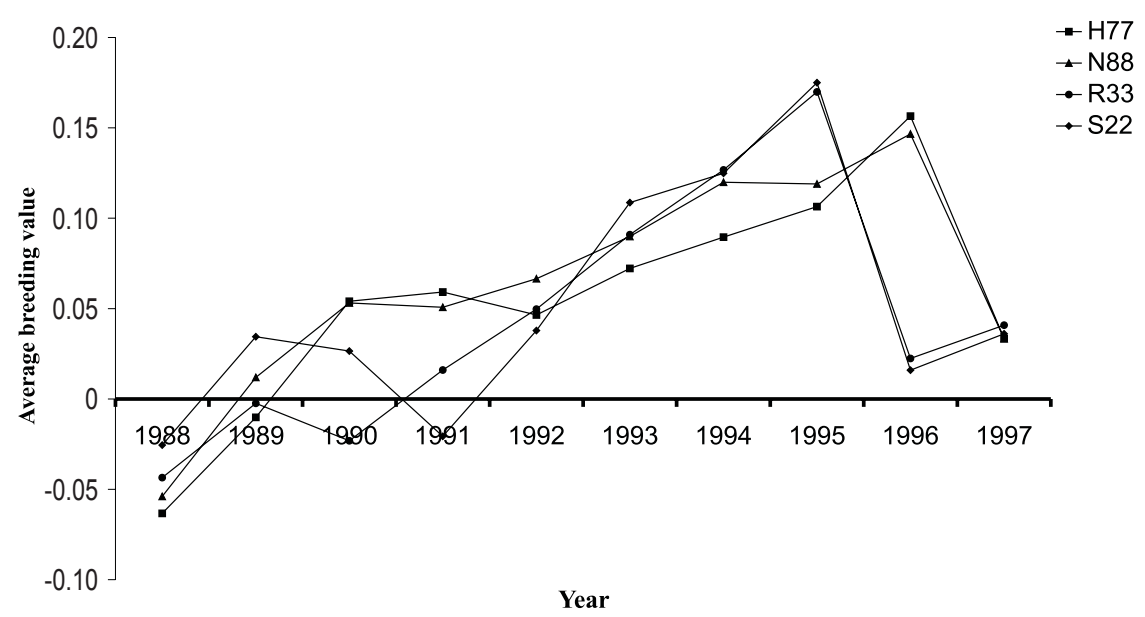

Figure 2. Genetic trends for hatchability

ever, some fluctuations of mean breeding values were registered. Similar tendencies for both traits were observed. As already mentioned, the genetic variability of these traits estimated under a Bayesian threshold model is higher as compared to the one from the linear model (Szwaczkowski et al., 2002). It results in larger changes in the average genetic effects over time. Differences among strains occurred, especially in the last two generations. It should be stressed that both phenotypic and genetic trends of productive traits for all the strains analysed were satis- 
factory (Piotrowski, unpublished data). The results show that direct selection for increased egg production results in non-negative genetic trends of these reproductive traits in the population studied.

\section{REFERENCES}

Beaumont C., Millet N., Le Bihan-Duval E., Kipi A., Dupuy V., 1997. Genetic parameters of survival to the different stages of embryonic death in laying hens. Poultry Sci. 76, 1193-1196

Brah G. S., Jagtar S.S., Chaudhary M.L., 1999. Variance and covariance component analysis of incubational mortality in chickens. Arch. Tierzucht 42, 295-302

Chaudhary M.L., Sandhu J.S., Brah G.S., 1987. Genetic, phenotypic and environmental relationships of fertility and hatchability with other economic traits in White Leghorns. J. Anim. Breed. Genet. 104, 169-174

Foerster A., 1993. Zuechterische Moeglichkeiten einer Verbesserung der Schlupfrate in Reinzuchtlinien eines Zuchtprogrammes fuer braune Legehybriden. PhD. Thesis, Institute fuer Tierzucht und Tierhaltung der Christian-Alberts Universität, Kiel (Germany)

Gianola D., Foulley J.L., 1983. Sire evaluation for ordered categorical data with a threshold model. Genet. Sel. Evolution 15, 201-223

Gowe R.S., Fairfull R.W., McMillan I., Schmidt G.S., 1993. A strategy for maintaining high fertility and hatchability in a multiple-trait egg stock selection program. Poultry Sci. 72, 1433-1448

Hartmann W., 1989. From Mendel to multi-national in poultry breeding. World Poultry Sci. J. 45, $5-26$

Hartmann C., Strandberg E., Rydhmer L., Johansson K., 2002. Genetic relations between reproduction, chick weight and maternal egg composition in a White Leghorn line. Acta Agr. Scand., Sect. A, Anim. Sci. 52, 91-101

Jassim E.W., Grossman M., Koops W.J., Luykx R.A.J., 1996. Multiphasic analysis of embryonic mortality in chickens. Poultry Sci. 75, 464-471

Matos C.A.P., Thomas D.L., Gianola D., Perez-Enciso M., Young L.D., 1997. Genetic analysis of discrete reproductive traits in sheep using linear and nonlinear models. I. Estimation of genetic parameters. J. Anim. Sci. 75, 76- 87

Moliński K., Szydłowski M., Szwaczkowski T., Dobek A., Skotarczak E., 2003. An algorithm for genetic variance estimation of reproductive traits under a threshold model. Arch. Tierzucht 46, 85-91

Piotrowski P., Szwaczkowski T., 2002. Impact of data transformation on the heritability estimates of reproductive traits in laying hens. J. Anim. Feed Sci. 11, 485-495

Sewalem A., Johansson K., Carlgren A.B., Wilhelmson M., Lillpers K., 1998. Are reproductive traits impaired by selection for egg production in hens? J. Anim. Breed. Genet. 115, 281-297

Sewalem A., 1998. Genetic study of reproduction traits and their relationship to production traits in White Leghorn lines. PhD. Thesis, Swedish University of Agricultural Sciences, Uppsala

Sorensen D.A., Andersen S., Gianola D., Korsgaard I., 1995. Bayesian inference in threshold models using Gibbs sampling. Genet. Sel. Evolution 27, 229-249

Szwaczkowski T., Moliński K., Szydłowski M., Skotarczak E., Piotrowski P., Dobek A., 2002. Comparison of heritability estimates of hatchability layer traits obtained with linear and threshold model. Proceedings of 7-th World's Congress on Genetics Applied to Livestock Production, Montpellier, Book of Abstracts, p. 86 
Szwaczkowski T., Piotrowski P., 1998. On transformation of the hatchability traits in laying fowl. Proceedings of XVIII-th Genetic Days, Česke Budejovice (Czech Republic). Czech J. Anim. Sci. 43,428

Szwaczkowski T., Wężyk S., Piotrowski P., Cywa-Benko K., 2000. Direct and maternal genetic and enviromental effects for fertility and hatchability in laying hens. Arch. Geflügelk. 64, 115-120

Van Heelsum A.M., Lewis R.M., Haresign W., Williams S.P., Davies M.H., 2001. Non-normality in carcass quality measurements and effects on the genetic evaluation of Bluefaced Leicester sheep. Livest. Prod. Sci. 69, 113-127

Van Tassel C.P., Casela G., Pollak E.J., 1995. Effects of selection on estimates of variance components using Gibbs sampling and restricted maximum likelihood. J. Dairy Sci. 78, 678-692

Van Tassel C.P., Van Vleck L.D., Gregory K.E., 1998. Bayesian analysis of twinning and ovulation rates using a multiple-trait threshold model and Gibbs sampling. J. Anim. Sci. 76, 2048-2061

Wright C.R., Stern H.S., Berger P.J., 2000. Comparing traditional and Bayesian analyses of selection experiments in animal breeding. J. Agr. Biol. Environ. Statistics 5, 240-256

Yoo B.H., Wienties E., 1991. Rate of decline in hatchability with preincubation storage in chicken eggs depends on genetic strain. Brit. Poultry Sci. 32, 733-740

\section{STRESZCZENIE}

\section{Bayesowskie estymatory wariancji genetycznej płodności i wylęgowości uzyskane na podsta- wie modelu progowego zwierzęcia}

Badano zmienność genetyczną płodności i wylęgowości kur nieśnych z czterech rodów objętych selekcją na cechy produkcyjne. Dane objęły 9 pokoleń, a liczba obserwowanych kur w poszczególnych rodach wynosiła od 2015 do 5386 . Cechy traktowano jako binarne i opisano modelem progowym, przy czym nieobserwowaną zmienną ciagłą analizowano na podstawie modelu zwierzęcia. Parametry modelu oszacowano metodą Gibbs sampling. Oceny punktowe odziedziczalności płodności były stosunkowo wysokie i wynosiły od 0,38 do 0,46 . Wartości odziedziczalności wylęgowości wynosiły od 0,22 do 0,24 . We wszystkich rodach trend genetyczny w zakresie obydwóch cech był nieujemny. 